\title{
Application of GNSS derived precipitable water vapour prediction in West Africa
}

https://doi.org/10.1515/jogs-2019-0005

Received October 2, 2018; accepted February 12, 2019

\begin{abstract}
Atmospheric water vapour, a major component in weather systems serves as the main source for precipitation, provides latent heat which helps maintain the earth's energy balance and a major parameter in Numerical Weather Prediction (NWP) models. An observational technique based on the Global Navigation Satellite System (GNSS) has made it possible to easily retrieve Precipitable Water (PW) at station's antenna position with very high spatial and temporal variabilities. GNSS techniques are superior to ground-based and balloons sensors in terms of accuracy, ease of use, wider coverage and easier assimilation into NWP models. This study sought to use prediction models using daily observational data from Four (4) International GNSS Service stations in West Africa. The best prediction model can be used in cases of station outages and to predict PW over data poor regions using computed Zenith Tropospheric Delays (ZTD). gLAB software was used to process the stations' data in Precise Point Positioning mode and PW were retrieved using station's temperature and pressure values. Computed PW were compared against Total Column Water Vapour from ERA-Interim Reanalysis data in 2016. Correlation coefficient $\left(R^{2}\right)$ values ranging from $0.947-0.995$ were obtained for the four stations. With computed PW's, three regression models were tested to find the best-fit with PW as the dependent variable and ZTD being the independent variable. The quadratic model gave the highest $R^{2}$ and lowest RMSE values as against the linear and exponential models. Time series forecasts models such as moving average, autoregressive, exponential smoothing and autoregressive integrated moving average were also employed. The forecasts results were compared against ZTD with autoregressive model reporting the highest $R^{2}$ and lowest RMSE amongst the forecast models developed.
\end{abstract}

Keywords: GNSS, precipitable water, regression model, time series, zenith tropospheric delays

\section{Introduction}

Water vapour forms over $99 \%$ of the atmospheric moisture and it is the main source of atmospheric energy that has a strong effect on climate on a longer time scale and drives the development of weather systems on short time scale (REMSSTeam, 2018; Guerova, 2003). Water vapour as a primary greenhouse gas traps more heat than the other greenhouse gases making its movement and associated latent heat of vapourization responsible for about $50 \%$ of global atmospheric heat transfer (Ramanathan and Feng, 2009; Karl and Trenberth, 2003; Raval and Ramanathan, 1989). These processes in-turn helps to determine the amount of precipitation a region receives. More water vapour is contained in the warmer atmosphere and as a greenhouse gas, it absorbs more thermal infra-red energy radiated from the earth. With increases in water vapour contents in the atmosphere, most will condense into clouds which are able to reflect incoming solar radiation which prevents more energy which will heat the earth up from reaching its surface (Soden et al., 2002; Held and Soden, 2000; Wang et al., 1976). Perlman (2016) gives detailed account of the water cycle with illustrations, interactive maps and figures.

Knowledge of atmospheric water vapour contents, variability and state makes it an essential component of the earth's climate system (Wolfe and Gutman, 2000). Water vapour amounts and variabilities are key parameters in weather forecasting and numerical weather models (Kaufmann et al., 2003; Johnsen, 2001; Bevis et al., 1996). Conventional methods such as radiosondes, sun photometers or hygrometer when used to measure atmospheric water vapour have several limitations. These are coverage limita-

\footnotetext{
^Corresponding Author: A. Acheampong: Kwame Nkrumah University of Science and Technology Kumasi, Ghana, E-mail: aaacheampong.coe@knust.edu.gh; akwasi_afrifa@hotmail.com K. Obeng : Kwame Nkrumah University of Science and Technology, Ghana
} 
tions, expensive to deploy and are affected by weather conditions such as heavy clouds and precipitation (Campos et al., 2018; Acheampong, 2016). With the advent of GNSS, atmospheric water vapour can be determined easily and to a higher accuracy and it is not limited by area or weather conditions (Guerova et al., 2016; Li et al., 2015; Bosy et al., 2010; Duan et al., 1996; Bevis et al., 1992). The objectives of this study were to determine Precipitable Water (PW) from GNSS signals over four International GNSS Service (IGS) stations and to develop a PW prediction model based on regression and time series models to predict trends. The study is inspired by events of station outages and/or nonfunctioning due to mechanical or receiver firmware issues.

\section{IGS Stations Used}

Four IGS stations were used for this study and each can be found in Benin, Cote d'Ivoire, Gabon and Senegal. Details of these stations are shown in Table 1 and visual locations shown in Fig. 1.

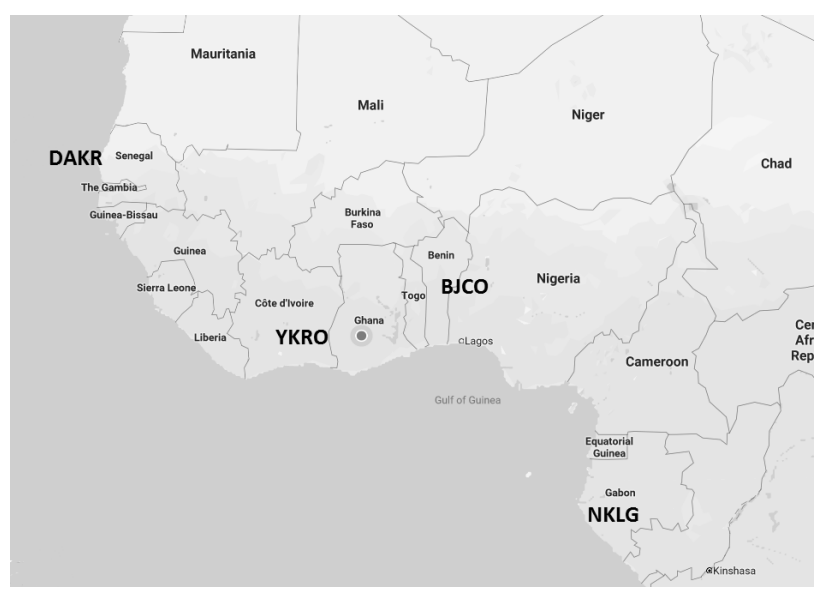

Figure 1: Map of West Africa showing the four IGS Stations used (GoogleMap, 2018)

\section{Methodology}

GPS daily observation data for the entire 2016 were used for model development and data for the months of February, May, August and November in 2017 were used for validation and testing. The data were obtained from The Crustal Dynamics Data Information System (CDDIS) of the National Aeronautics and Space Administration (NASA) using their file transfer protocol (FTP) (Noll, 2010). Aside observational data, navigational files, IONEX (Schaer et al., 1998), ANTEX (Rothacher and Schmid, 2010), differential core bias (DCB) (Montenbruck et al., 2014) were downloaded and used.

The steps taken to determine Precipitable Water (PW) and best model for prediction based on ZTD from GNSS signals are as follows:

(i) GNSS data processing using gLAB software in Precise Point Positioning (PPP) mode.

(ii) Extraction of ZTD.

(iii) Extraction of Surface Pressure, Temperature and TCWV.

(iv) Computation of PW.

(v) Prediction models (regression \& time series) development.

(vi) Model Validation.

(i) GNSS data processing using PPP - GNSS data such as navigation, observation, Antenna Exchange Format (ANTEX) and precise ephemeris and clock files were used in the gLAB software (Hernandez-Pajares et al., 2010). The parameters set in the software are an elevation mask of $5^{\circ}$ and data decimation of 300 secs. Simple nominal and Niell mapping function for tropospheric delay modelling, IONEX files for the ionospheric correction and DCB for code observation corrections at same and/or different frequencies (Subirana et al., 2013; Wang et al., 2016). The software output precise receiver coordinates, satellite azimuth \& elevations, signal flight times, dilution of precisions, ionospheric corrections, tropospheric delays, etc. Further details and statistics on gLAB processed coordinates and IGS antenna position coordinates and zenith path delay products are given in Acheampong (2016) and Acheampong et al. (2015).

(ii) Extraction of ZTD - Tropospheric Delays are significant error source which affects the GNSS signal propagation time. The delay comes in two components namely; hydrostatic and wet parts. They are also referred to as Zenith Hydrostatic Delay (ZHD) and Zenith Wet Delay (ZWD) when delays are mapped onto the zenith. The slant delays are initially computed with respect to each satellite and then using appropriate mapping functions they are mapped unto the zenith (Misra and Enge, 2012; Seeber, 2003). The total tropospheric delays can be expressed mathematically as $Z T D=Z H D+Z W D$.

(iii) Extraction of Surface Pressure, Temperature and TCWV - Weather data such as Surface Pressure, Temperature and TCWV are needed in the accurate and 
Table 1: IGS Stations used

\begin{tabular}{|c|c|c|c|c|c|c|}
\hline Site ID & Country & Latitude & Longitude & $\begin{array}{l}\text { Ellip. } \\
\text { Height }\end{array}$ & Receiver Type & Antenna \\
\hline $\mathrm{BJCO}$ & Benin & $06^{\circ} 23^{\prime} 04.79^{\prime \prime}$ & $02^{\circ} 27^{\prime} 00.08^{\prime \prime}$ & $30.700 \mathrm{~m}$ & Trimble Net R5 & TRM59800 \\
\hline YKRO & $\begin{array}{l}\text { Cote } \\
\text { d'Ivoire }\end{array}$ & $06^{\circ} 52^{\prime} 14.01^{\prime \prime}$ & $-05^{\circ} 14^{\prime} 24.33^{\prime \prime}$ & $270.000 \mathrm{~m}$ & $\begin{array}{l}\text { Rogue } \\
\text { SNR-800 }\end{array}$ & AOAD/M_T \\
\hline NKLG & Gabon & $00^{\circ} 21^{\prime} 14.06 "$ & $09^{\circ} 40^{\prime} 19.65^{\prime \prime}$ & $31.496 \mathrm{~m}$ & Trimble Net R9 & TRM59800 \\
\hline DAKR. & Senegal & $14^{\circ} 43 / 04.40^{\prime \prime}$ & $-17^{\circ} 26^{\prime} 22.10^{\prime \prime}$ & $51.000 \mathrm{~m}$ & TPS Net-G3A & TPSCR..G3 \\
\hline
\end{tabular}

precise determination of PW from tropospheric delays. Although there are models that do not employ weather data in the determination of PW (Subirana et al., 2013), but this study considered models [shown in Eq (1)] that use weather data for PW determination (Bevis et al., 1994; Choy et al., 2013; Karabatić and Weber, 2009).

$$
P W=\frac{Z T D-\frac{2.2767 \star \frac{P}{105}}{0.997337}}{0.00461\left(k_{2}+\frac{k_{3}}{T_{m}}\right)},
$$

$P$ is the pressure in Pascal, $k_{2}$ and $k_{3}$ are empirical coefficients representing the constants of the deviation of the atmospheric constituents from an ideal gas which is based on laboratory estimates. $\mathrm{Tm}$ is the mean temperature at the observation site in Kelvins derived from the surface temperature, Ts, as expressed in Eq. (2). Following Chen and Yao (2015), these coefficients were employed to compute $T_{m}$ they, day of year (doy), the average $\left(a_{0}\right)$, annual variation coefficients $\left(a_{1}, b_{1}\right)$ semiannual variation coefficients $\left(a_{2}, b_{2}\right)$ diurnal variation coefficients $\left(a_{3}, b_{3}\right)$, lapse rate of $6.5 \mathrm{~K} / \mathrm{km}(\delta)$ and station height $(H)$.

$$
\begin{aligned}
& T_{m}=a_{0}+a_{1} \cos \left(\frac{\text { doy }}{365.25} 2 \pi\right)+b_{1} \sin \left(\frac{\text { doy }}{365.25} 2 \pi\right) \\
& +a_{2} \cos \left(\frac{d o y}{365.25} 4 \pi\right)+b_{2} \sin \left(\frac{d o y}{365.25} 4 \pi\right) \\
& +a_{3} \cos \left(\frac{T_{s}}{365.25} 2 \pi\right)+b_{3} \sin \left(\frac{T_{s}}{365.25} 2 \pi\right)+\delta H
\end{aligned}
$$

Weather variables for the observation days were extracted from European Centre for Medium-range Weather Forecasts (ECMWF) ERA-Interim datasets on a six-hour interval $(0,6,12$ \& 18 hours) for each day (Dee et al., 2011; Berrisford et al., 2009). In order to retrieve the weather data, day and time of observation, longitudes and latitudes of the grid nodes are needed. Table 2 shows the grid points used in the retrieval of weather data from ERA-Interim using the link http://apps.ecmwf.int/datasets/.

(iv) Computation of $\boldsymbol{P W}$ - Tropospheric delay is the bending and slowing down of GNSS signals in the troposphere. It is computed as slant delays during processing and using appropriate mapping functions, they are mapped unto the zenith for easier computations of PW. The software outputs the total tropospheric delays along the zenith direction as ZTD. The quantum of the delay ZTD is nearly proportional to the atmospheric water vapour (Foelsche and Kirchengast, 2001; Bevis et al., 1992). PW were computed using Eq. (1).

(v) Prediction model development - The focus of this study is to develop models to predict PW based on processed ZTD and retrieved TCWV. Following Voyant et al. (2012); Montgomery et al. (2012) and Danforth et al. (2007), linear models considered were quadratic $(y=$ $\left.a x^{2}+b x+c\right)$, linear $(y=a+b x)$ and exponential sequences $\left(y=a b^{x}\right)$. The variables used in the regression models are $y$ being the dependent variable, $x$ as the independent variable, $a$ is the y-intercept, $b$ is the slope of the line and $c$ is the squared vertical distance between each point $(x, y)$. The time series models were developed based on processed ZTD for predictions in case of station outages or malfunctioning. The models considered were exponential smoothing, autoregressive, moving averages and autoregressive integrated moving averages and they are shown in Eqs (3) - (6). The variables are $\gamma_{t}$ the forecast value, $\beta_{i}$ is a constant, $\gamma_{t-i}$ is the time-lagged series value, $\mu$ is the mean, $\phi$ is the slope coefficient and $\alpha$ being the smoothing constant which varies from 0 to 1 (Shumway and Stoffer, 2011; Cryer and Chan, 2008).

(a) Autoregression $(A R)$ - is a stochastic process in which weighted sum of past values are used as a basis for predicting future values. AR models are represented by Eq. (3);

$$
\gamma_{t}=\beta_{0}+\beta_{1 \gamma_{t-1}}+\beta_{2 \gamma_{t-2}}+\ldots+\beta_{i \gamma_{t-i}}
$$

(b) Moving Average (MA) - fits a linear regression of present data to predict future values. MA models are 
Table 2: The grid points used in scaling down the ERA-Interim model for weather data retrieval

\begin{tabular}{|c|c|c|c|c|c|c|c|c|}
\hline \multirow{2}{*}{ Site ID } & \multicolumn{2}{|c|}{ Top Left } & \multicolumn{2}{|c|}{ Top Right } & \multicolumn{2}{|c|}{ Bottom Left } & \multicolumn{2}{|c|}{ Bottom Right } \\
\hline & Lat $\left(^{\circ}\right)$ & Lon $\left(^{\circ}\right)$ & Lat $\left(^{\circ}\right)$ & Lon $\left(^{\circ}\right)$ & Lat $\left(^{\circ}\right)$ & Lon $\left(^{\circ}\right)$ & Lat $\left(^{\circ}\right)$ & Lon $\left(^{\circ}\right)$ \\
\hline $\mathrm{BJCO}$ & 7 & 1 & 7 & 3 & 5 & 1 & 5 & 3 \\
\hline DAKR & 15 & -18 & 15 & -16 & 13 & -18 & 13 & -16 \\
\hline NKLG & 1 & 8 & 1 & 10 & -1 & 8 & -1 & 10 \\
\hline YKRO & 7 & -6 & 7 & -4 & 5 & -6 & 5 & -4 \\
\hline
\end{tabular}

represented by Eq. (4);

$$
\gamma_{t}=\frac{\gamma_{t-1}+\beta_{2 \gamma_{t-2}}+\ldots+\beta_{i \gamma_{t-i}}}{i}
$$

(c) Autoregressive Integrated Moving Average (ARIMA) merges linear regression in moving averages. ARIMA models are represented by Eq. (5);

$$
\gamma_{t}=\mu+\gamma_{t-1}+\varnothing\left(\gamma_{t-2}+\ldots+\gamma_{t-i}\right)
$$

(d) Exponential Smoothing (ES) - unlike moving averages in which past observations are weighted equally, exponential smoothing assigns decreasing weights over time. ES models are represented by Eq. (6);

$$
\gamma_{t}=\alpha \beta_{t-1}+(1-\alpha) \gamma_{t-1}
$$

(vi) Model Validation - After the coefficients and constants were computed using the models presented in sub-section $V$, the models were validated using data from the four stations in the months of February, May, August and November of 2017. Validation was done comparing computed-PW as against derived-PW using ZTD as an independent variable in the models. Correlation coefficient $\left(R^{2}\right)$ and Root Mean Square Error (RMSE) were computed and the threshold of these statistics were used to select the best model for PW prediction.

\section{Results}

In order to select the best model for prediction, PW for the year 2016 were computed using Eqs. (1) \& (2) and compared against TCWVretrieved from the numerical prediction model. $R^{2}$ and descriptive statistics were computed for and can be found in Table 3 as well as graphs representing the relationship between computed PW and TCWV in Figs. 2 \& 3.

With the results showing higher correlation between the two datasets, the computed PW and their correspond-
Table 3: $R^{2}$ and descriptive statistics of TCWV and computed PW for 2016

\begin{tabular}{lllll}
\hline $\begin{array}{l}\text { IGS } \\
\text { Station }\end{array}$ & $\boldsymbol{R}^{2}$ & & $\begin{array}{l}\text { Computed } \\
\text { PW }\end{array}$ & TCWV \\
\hline \multirow{2}{*}{ BJCO } & \multirow{2}{*}{0.982} & Mean & 51.7980 & 51.6110 \\
& & Std Err & 0.5216 & 0.4986 \\
& & $95 \%$ C.I. & 1.0534 & 0.9811 \\
\hline \multirow{2}{*}{ DAKR } & \multirow{2}{*}{0.947} & Mean & 39.2478 & 38.4470 \\
& & Std Err & 0.7005 & 0.7239 \\
& & $95 \%$ C.I. & 1.3957 & 1.4242 \\
\hline \multirow{2}{*}{ NKLG } & \multirow{2}{*}{0.995} & Mean & 53.1204 & 52.1317 \\
& & Std Err & 0.3064 & 0.2950 \\
& & $95 \%$ C.I. & 0.6103 & 0.5804 \\
\hline \multirow{2}{*}{ YKRO } & \multirow{3}{*}{0.970} & Mean & 36.1260 & 37.8520 \\
& & Std Err & 0.5614 & 0.5723 \\
& & $95 \%$ C.I. & 1.1079 & 1.1268 \\
\hline
\end{tabular}

ing ZTDs were used to determine constants and coefficients for the regression and time series models. The values were used in predicted PW derivation based on Eqs. (3) - (6). After the predicted PW were derived, they were compared with computed PW and results are shown in Tables 4 \& 5 .
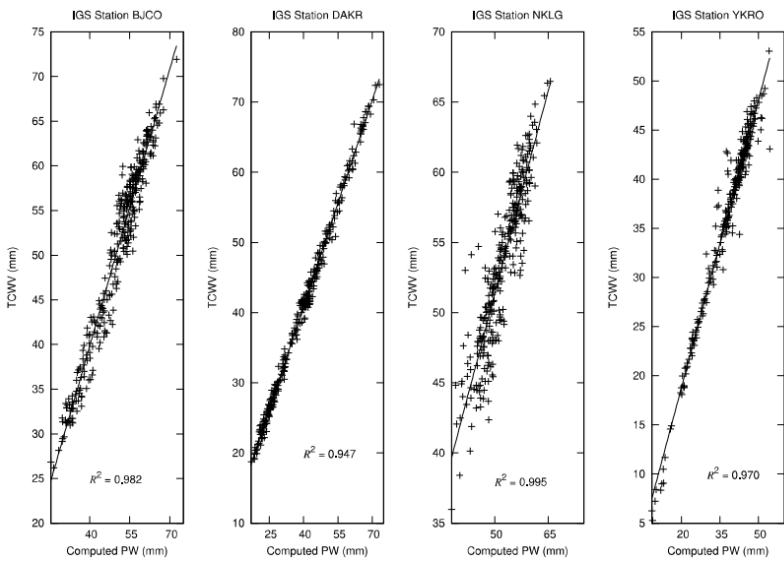

Figure 2: Correlation plots of computed PW for the four IGS Stations in West Africa against TCWV retrieved from ERA-Interim reanalysis data 

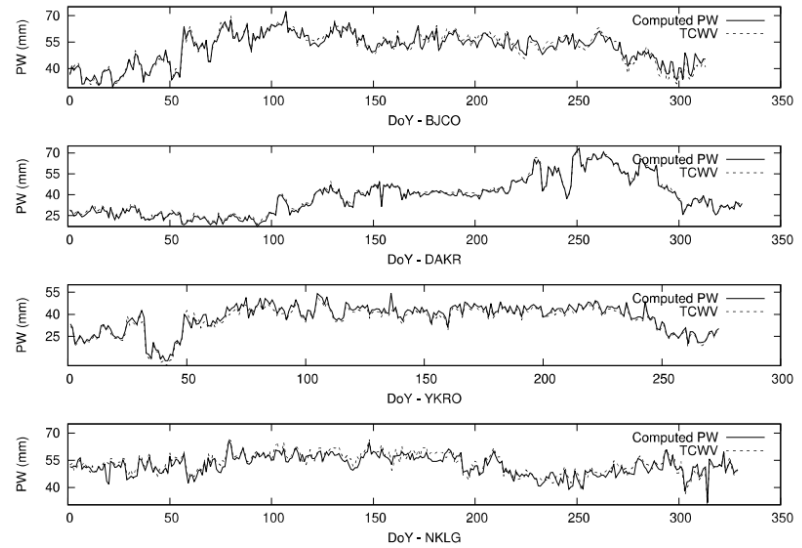

Figure 3: Precipitable Water and Total Column Water Vapour plots against Day of Year for the four IGS Stations in West Africa

Table 4: $R^{2}$ and $R M S E$ between computed PW and predicted PW using regression models

\begin{tabular}{llclll}
\hline \multirow{2}{*}{ Model } & \multicolumn{2}{c}{ BJCO } & \multicolumn{2}{c}{ DAKR } \\
\cline { 2 - 3 } & $R^{2}$ & RMSE & $R^{2}$ & RMSE \\
\hline Linear & 0.7861 & 0.4660 & 0.9985 & 0.3530 \\
Exponential & 0.7859 & 0.4480 & 0.9985 & 0.3510 \\
Quaratic & 0.7602 & 0.4470 & 0.9987 & 0.2310 \\
& \multicolumn{2}{c}{ NKLG } & \multicolumn{2}{c}{ YKRO } \\
Linear & 0.9878 & 0.5960 & 0.9620 & 0.4960 \\
Exponential & 0.9872 & 0.5240 & 0.9610 & 0.5060 \\
Quaratic & 0.9893 & 0.4890 & 0.9890 & 0.4490 \\
\hline
\end{tabular}

\section{Discussion}

For the period of this study, which was the year 2016, PW were computed for four IGS stations (BJCO,

DAKR, NKLG and YKRO). The computed PW were compared against its corresponding TCWV in terms of $R^{2}$, descriptive statistics and graphs were generated as shown in Table 3 and Figs. $2 \& 3$.

It can be seen that all the stations have $R^{2}$ values closer to 1 showing a stronger linear relationship between the two datasets. IGS station NKLG had the biggest $R^{2}$ of 0.995 with DAKR being the smallest with $R^{2}$ of 0.947 .

With the computed PW and TCWV, regression models namely; linear, exponential and quadratic were developed. After the development of the model, data validation was done using monthly data for February, May, August and November of 2017. PW for those periods were com-
Table 5: $R^{2}$ and RMSE for the computed PW and predicted PW from time series models

\begin{tabular}{clll}
\hline IGS Station & Model & $R^{2}$ & RMSE \\
\hline \multirow{4}{*}{ BJCO } & MA & -0.2540 & 0.0441 \\
& ES & 0.5412 & 0.0250 \\
& ARIMA & 0.2471 & 0.0226 \\
& AR & 0.9800 & 0.0049 \\
\hline \multirow{5}{*}{ DAKR } & MA & -0.5550 & 0.0450 \\
& ES & 0.3561 & 0.0310 \\
& ARIMA & -0.7040 & 0.0346 \\
& AR & 0.9701 & 0.0045 \\
\hline \multirow{5}{*}{ NKLG } & MA & -0.7901 & 0.0276 \\
& ES & 0.0892 & 0.0390 \\
& ARIMA & 0.0570 & 0.0472 \\
& AR & 0.9841 & 0.0025 \\
\hline \multirow{5}{*}{ YKRO } & MA & 0.1635 & 0.0332 \\
& ES & 0.2630 & 0.0334 \\
& ARIMA & 0.3201 & 0.0980 \\
& AR & 0.9300 & 0.0060 \\
\hline
\end{tabular}

puted and compared with predicted PW for all models. $R^{2}$ and RMSE were computed for all stations as shown in Table 4. From Table 4, it is seen that quadratic regression model had the highest $R^{2}$ and lowest RMSE for all IGS stations making it the best regression model. These findings relate perfectly with works done to study the determination of post seismic decays from selected GNSS and SLR co-located sites by Sapota et al. (2014). In the study, the positional changes in XYZ directions for each IGS station was analyzed over a 10 -year period employing exponential and logarithm models for predictions. $R^{2}$ and RMSE were computed for station movements by comparing station XYZ shifts against model results, the exponential models were preferred because it had the highest $R^{2}$ and lowest RMSE for each coordinate position. Similar study carried out by Alshawaf et al. (2017) on estimation of decadal variations in atmospheric water vapour using ground-based GNSS at selected IGS sites in Germany. In the study, PW were computed from GNSS signals and compared against TCWV obtained from ERA-Interim's data, resultant correlation coefficients of 0.996 for GNSS against ERA-Interim and 0.987 for GNSS against meteorological data fall in line with similar values of $R^{2}$ obtained for this study. Again, Aon et al. (2017) conducted a study on modeling GPS Ionospheric scintillation using nonlinear regression techniques in Malaysia to monitor ionospheric scintillations during the 24th solar maximum from September 2013 to August 2014. They developed mathematical models based on first, second and third order polynomial and 
concluded that the second order polynomial was the best choice of model because it had the lowest RMSE amongst the other polynomial series.

Timeseries forecast models namely; Autoregression, Moving Average, Exponential Smoothing and Autoregression Integrated Moving Average were developed based on January 2016 data and compared with data for January 2017. The resulting $R^{2}$ and RMSE are shown in Table 5. From Table 5 Autoregression had the highest $R^{2}$ and lowest RMSE amongst all the models for each IGS station making it the best time series model amongst the rest.

\subsection{Conclusion}

In the determination of PW from tropospheric delays, parameters such as ZTD, temperature, pressure, some laboratory estimates and constants are needed. ZTD was obtained from GNSS data processing using gLAB. Temperature, pressure and TCWV were obtained from ECMWF ERAInterim datasets. Data for the years 2016 and 2017 from four IGS stations in West Africa were used. PW were computed using equations stated in Section §3. The computed PW were compared against TCWV and higher correlations between the two datasets were recorded. After the computation of PW, prediction models were developed based on regression models using ZTD and its corresponding computed PW as training data. Data from the months of February, May, August and November of 2017 were used to validate the models. $R^{2}$ and RMSE for the computed PW and predicted PW for each IGS station were computed for with the quadratic model recording the highest $R^{2}$ and lowest RMSE amongst the regression models. Similar statistics were undertaken for the four time series models considered and the Autoregression model reported the lowest RMSE and highest $R^{2}$. The best-fitting regression model was the quadratic and reported an uncertainty of 0.404 in its PW predictions. On the time series models, autoregression can confidently predict $\mathrm{PW}$ with uncertainties around 0.031. For further studies we hope to use ground-based sensors and surface variables to augment NWP model.

\section{References}

Acheampong A. A., 2016, Retrieval of integrated water vapour from GNSS signals for numerical weather predictions. PhD thesis, KNUST - Ghana.

Acheampong, A. A., Fosu, C., Amekudzi, L. K. and Kaas, E. 2015, Comparison of precipitable water over Ghana using GPS signals and reanalysis products. J. Geod. Sci. 5(1).
Alshawaf F., Dick G., Heise S., Balidakis K., Schmidt T. and Wickert J., 2017, Decadal variations in atmospheric water vapor time series estimated using GNSS, ERA-Interim, and synoptic data. In EGU General Ass. Conf. Abst. 19:2721.

Aon E. F., Ho Y. H., Othman A. R. and Shaddad R. Q., 2017, Modeling of GPS ionospheric scintillation using nonlinear regression technique. In Recent Trends in Info, and Comm. Tech.: 180-188. Springer.

Berrisford P., Dee D., Fielding K., Fuentes M., Kallberg P., Kobayashi S. and Uppala S., 2009, The ERA-Interim archive. ERA Report Series, (1):1-16.

Bevis M., Businger S., Chiswell S., Herring T. A., Anthes R. A., Rocken C. and Ware R. H., 1994, GPS meteorology: Mapping zenith wet delays onto precipitable water. J. Appl. Meteor., 33(3):379-386.

Bevis M., Businger S., Herring T. A., Rocken C., Anthes R. A. and Ware R. H., 1992, GPS meteorology: Remote sensing of atmospheric water vapor using the Global Positioning System. J. Geophy. Res: Atm, 97(D14):15787-15801.

Bevis M., Chiswell S., Businger S., Herring T. A. and Bock Y., 1996, Estimating wet delays using numerical weather analyses and predictions. Rad. Sci., 31(3):477-487.

Bosy J., Rohm W., Borkowski A., Kroszczynski K. and Figurski M., 2010 , Integration and verification of meteorological observations and NWP model data for the local GNSS tomography. Atm. Res., 96(4):522- 530.

Campos T. B., Sapucci L. F., Lima W. and Ferreira D. S., 2018, Sensitivity of numerical weather prediction to the choice of variable for atmospheric moisture analysis into the Brazilian global model data assimilation system. Atm., 9(4): 123.

Chen, P. and Yao, W. 2015, Gtm x: A new version global weighted mean temperature model. In China Satellite Navigation Conference (CSNC) 2015 Proceedings: Volume II. J. Sun et al. (eds.), pages 605-611. Springer.

Choy S., Wang C, Zhang K. and Kuleshov Y., 2013, GPS sensing of precipitable water vapour during the march 2010 Melbourne storm. Adv. Sp. Res., 52(9):1688-1699.

Cryer J. D. and Chan K. S., 2008, Time Series Analysis with Applications in R Second Edition. Springer Texts in Statistics, New York.

Danforth C. M., Kalnay E. and Miyoshi T., 2007, Estimating and correcting global weather model error. Mon. Wea. Rev., 135(2):281299.

Dee D. P., Uppala S. M., Simmons A. J., Berrisford P., Poli P., Kobayashi S., Andrae U., Bal-maseda M. A., Balsamo G., Bauer P., et al., 2011, The ERA-Interim reanalysis: Configuration and performance of the data assimilation system. Quart. J. Royal Met. Soc, 137(656):553597.

Duan J., Bevis M., Fang P., Bock Y., Chiswell S., Businger S., Rocken C., Solheim F., van Hove T., Ware R., et al., 1996, GPS meteorology: Direct estimation of the absolute value of precipitable water. J. Appl. Meteo., 35(6):830-838.

Foelsche U. and Kirchengast G., 2001, Tropospheric water vapor imaging by combination of ground-based and spaceborne GNSS sounding data. J. Geo. Res. 106(D21):27221-27231.

GoogleMap (2018). Map of West Africa. https://www.google.com.gh/maps/@6.8094745, 7.443851, 4.75z?hl=en.Google Maps.

Guerova G., 2003, Application of GPS derived water vapour for numerical weather prediction in Switzerland. PhD thesis, Bern University.

Guerova G., Jones J., Dousa J., Dick G., de Haan S., Pottiaux E., Bock 
O., Pacione R., Elgered G., Vedel H., et al., 2016, Review of the state of the art and future prospects of the ground-based GNSS meteorology in Europe. Atm. Mea. Tech., 9(11):5385.

Held I. M. and Soden B. J., 2000, Water vapor feedback and global warming. Ann. Rev. Energy and Env., 25(l):441-475.

Hernandez-Pajares M., Juan J., Sanz J., Ramos-Bosch P., Rovira-Garcia A., Salazar D., Ventura-Traveset J., Lopez-Echazarreta C., and Hein G., 2010, The ESA/UPC GNSS-lab tool (gLAB). In Proc. of the 5th ESA Workshop on Sat Nav Tech (NAVITEC 2010), ESTEC, Noordwijk, The Netherlands.

Johnsen K. P., 2001, GPS water vapour estimates compared with a nwp model within the BALTEX region. In IEEE Geosci and R Sen Symp, IGARSS'01, 3:1536-1538.

Karabatic A. and Weber R., 2009, Use of PPP to derive troposphere zenith wet delays of GNSS signals to support weather forecast models. 10th Osterreichischer Geodatentag.

Karl T. R. and Trenberth K. E., 2003, Modern global climate change. Sci, 302(5651):1719-1723.

Kaufmann P., Schubiger F. and Binder P., 2003, Precipitation forecasting by a mesoscale numerical weather prediction (NWP) model: eight years of experience. Hyd. and Ear. Sys. Sci., 7(6):812-832.

Li X., Dick G., Lu C., Ge M., Nilsson T., Ning T., Wickert J. and Schuh H., 2015, Multi-GNSS meteorology: Real-time retrieving of atmospheric water vapor from BeiDou, Galileo, GLONASS and GPS observations. IEEE, Trans Geosci. R. Sens. 53(12):6385-6393.

Misra P. and Enge P., 2012, Global Positioning System: Signals, Measurements and Performance. Revised Second Edition. GangaJamuna Press. Lincoln Massachusetts.

Montenbruck O., Hauschild A. and Steigenberger P., 2014, Differential code bias estimation using Multi-GNSS observations and global ionosphere maps. J. Inst. Nav., 61(3):191-201.

Montgomery D. C., Peck E. A. and Vining G. G., 2012, Introduction to linear regression analysis. 5th Ed. John Wiley \& Sons, Hoboken, New Jersey.

Noll C. E., 2010, The crustal dynamics data information system: A resource to support scientific analysis using space geodesy. Adv. Sp. Res., 45(12): 1421-1440.

Perlman H., 2016, Summary of the water cycle. The USGS Water Science School, http://water.usgs.gov/eduwatercyclesummary. html. Last modified: Dec-2016, Accessed: May-2018.
Ramanathan V. and Feng Y., 2009, Air pollution, greenhouse gases and climate change: Global and regional perspectives. Atm. Env., 43(l):37-50.

Raval A. and Ramanathan V., 1989, Observational determination of the greenhouse effect. Nat, 342(6251):758.

REMSSTeam, 2018, Atmospheric water vapor. Remote Sensing Systems, http://www.remss.com/measurements/atmosphericwater-vapor/. Accessed: May-2018.

Rothacher M. and Schmid R., 2010, ANTEX: The antenna exchange format version 1.4. Forschungseinrichtung Satellitengeodasie, TU Miinchen (ftp://igs.org/pub/station/general/antexl4.txt).

Sapota M., Szafranek K., Bogusz J., Figurski S. and Nykiel G., 2014, Determination of post-seismic decays from selected GNSS and SLR co-located sites. 14th SGEM GeoConference on Info. Geo. and Rem. Sens. 2:199-206.

Schaer S., Gurtner W. and Feltens J., 1998, IONEX: The ionosphere map exchange format version 1. In IGS AC Workshop, Darmstadt, Germany, 9(11).

Seeber G., 2003, Satellite Geodesy: Foundations, Methods, and Applications. Walter de Gruyter. Berlin.

Shumway, R. H. and Stoffer, D. S. 2011, Time series regression and exploratory data analysis. In Time series analysis and its applications, pages 47-82. Springer.

Soden B. J., Wetherald R. T., Stenchikov G. L. and Robock A., 2002, Global cooling after the eruption of Mount Pinatubo: A test of climate feedback by water vapor. Sci. 296(5568):727-730.

Subirana J. S., Hernandez-Pajares M. and Juan Zornoza J. M., 2013, GNSS Data Processing: Fundamentals and Algorithms. Vol I k, II. ESA Comm.

Voyant C., Muselli M., Paoli C. and Nivet M. L., 2012, Numerical weather prediction (NWP) and hybrid ARMA/ANN model to predict global radiation. Energy. 39(l):341-355.

Wang N., Yuan Y., Li Z., Montenbruck O. and Tan B., 2016, Determination of differential code biases with Multi-GNSS observations. J. Geod. 90. (3):209-228.

Wang W. C., Yung Y. L., Lacis A. A., Mo T. and Hansen J. E., 1976, Greenhouse effects due to manmade perturbations of trace gases. Sci. 194(4266):685-690.

Wolfe D. E. and Gutman S. I., 2000, Developing an operational, surface-based, GPS, water vapor observing system for NOAA: Network design and results. J. Atmos. Oce. Tech. 17(4):426-440. 